NASA Technical Memorandum 103190

AIAA-90-2579

\title{
Arcjet Load Characteristics
}

John A. Hamley

Lewis Research Center

Cleveland, Ohio

(NASA-TM-103190) ARCJET LOAD
CHAPACTFRISTICS (NASA) $18 \mathrm{P}$

$\operatorname{CSCL~} 21 \mathrm{H}$

N9O-25191

Unclas

0289153

Prepared for the

21st International Electric Propulsion Conference cosponsored by the AIAA, DGLR, and JSASS

Orlando, Florida, July 18-20, 1990 


\title{
ARCJET LOAD CHARACTERISTICS
}

\author{
John A. Hamley \\ National Aeronautics and Space Administration \\ Lewis Research Center \\ Cleveland, Ohio 44135
}

\begin{abstract}
Experiments were conducted to define the interface characteristics and constraints of $1 \mathrm{~kW}$ class arcjets run on simulated decomposition products of hydrazine and power processors. The impacts of power supply output current ripple on arcjet performance were assessed by variation of the ripple frequency from $100 \mathrm{~Hz}$ to $100 \mathrm{kHz}$ with $10 \%$ peakto-peak ripple amplitude at $1.2 \mathrm{~kW}$. Ripple had no significant effects on thrust, specific impulse or efficiency. The impact of output ripple on thruster lifetime was not assessed.

The static and dynamic impedances of the arcjet were quantified with two thrusters of nearly identical configuration. Superposition of an AC component on the DC arc current was used to characterize the dynamic impedance as a function of flow rate and DC current level. A mathematical model was formulated from these data. Both the static and dynamic impedance magnitude were found to be dependent on mass flow rate. The amplitude of the AC component was found to have little effect on the dynamic impedance. Reducing the $D C$ level from 10 to 8 amps led to a large change in the magnitude of the dynamic impedance with no observable phase change. The impedance data compared favorably between the two thrusters.
\end{abstract}

\section{NOMENCLATURE}

$\begin{array}{ll}\mathrm{A}_{\mathrm{p}-\mathrm{p}} & \text { Amperes peak-to-peak, } \mathrm{A} \\ \mathrm{AC} & \text { Alternating current } \\ \mathrm{C} & \text { Arcjet dynamic impedance gain } \\ & \text { constant } \\ \mathrm{DC} & \text { Direct current } \\ \mathbf{f} & \text { Frequency, } \mathrm{Hz} \\ \mathrm{i}_{\mathrm{ac}} & \text { AC arc current, } \mathrm{A} \\ \mathrm{i}_{\mathrm{arc}} & \text { Arc current (total), } \mathrm{A} \\ \mathrm{i}_{\mathrm{dc}} & \text { DC arc current, } \mathrm{A} \\ \mathbf{j} & \sqrt{-1} \\ \mathrm{~K}_{\mathbf{i}} & \text { Gain constant for a specific } \\ & \text { pole-zero pair } \\ \mathrm{m} & \text { Total number of zeros } \\ \mathbf{n} & \text { Total number of poles } \\ \mathrm{p}_{\mathrm{i}} & \text { Dynamic impedance pole } \\ \mathrm{prrms}_{\mathrm{m}} & \text { RMS power, W } \\ \mathrm{q}_{\mathrm{i}} & \text { Dynamic impedance zero }\end{array}$

$\mathbf{S}$
$T$
$v_{\mathrm{ac}}$
$\mathrm{v}_{\mathrm{arc}}$
$\mathrm{v}_{\mathrm{dc}}$
$\mathrm{z}_{\mathrm{d}}$
$\theta$
$\tau$

Complex frequency

variable, $j 2 \pi f$

Thrust,g

AC arc voltage, $V$

Arc voltage (total), $\mathrm{V}$

$D C$ arc voltage, $V$

Dynamic impedance, $\Omega$

Impedance phase angle,

degrees

Transportation lag, seconds

\section{INTRODUCTION}

Arcjets were first considered as advanced propulsion devices in the 1950 's, and this early research program carried into the 1960 's. At this time, NASA's interest was primarily in planetary missions and research centered mainly on high powered arcjets with hydrogen propellant. ${ }^{1-4}$ Ammonia was also considered as an alternate propellant. Arcjets in the 1 to $2 \mathrm{~kW}$ class were considered for an auxiliary propulsion role, and these devices were run with some success on hydrogen propellant. ${ }^{5,6}$ Limited efforts to run the devices at these lower power levels on storable propellants met with little success. ${ }^{7}$ In 1965 , a review of these programs was presented by Wallner and Csika. ${ }^{8}$

Interest in arcjets renewed in the last decade, especially low power devices run on storable propellants. A 1-2 kW device was selected for northsouth stationkeeping missions (NSSK) on geosynchronous spacecraft. Current programs have demonstrated stable operation of these devices over a wide range of power levels and mass flow rates. Specific impulse values in the range of 450 to 550 seconds have been demonstrated at power levels and propellant pressures expected in a NSSK mission.914

In response to the need for system hardware, pulse width modulated (PWM) switching power supplies with integral starting circuits were designed to provide reliable start-up and steady-state operation with vortex flow stabilized arcjets ${ }^{15}$. These power processing units produced $13 \mathrm{kHz}$ ripple of approximately 1.5 ampere peak-to-peak amplitude, however, the effect of ripple on arcjet performance was unknown. Preliminary testing indicated a relatively fast response in the arc column, leading to a step response specification on the order of 500

Copyright (C) 1990 by the American Institute of Aeronautics and Astronautics, Inc. No copyright is asserted in the United States under Title 17, U.S. Code. The U.S. Government has a royalty-free license to exercise all rights under the copyright claimed herein for Governmental purposes. All other rights are reserved by the copyright owner. 
$\mu s .{ }^{15-18}$ No detailed work to characterize the dynamic impedance of the arcjet was done during the development of the power processors, however, a preliminary investigation to characterize the dynamic impedance was conducted afterward, which developed the methods used here. 19

This paper presents the results of initial efforts to evaluate and characterize the arcjet/power processor interface. First, the static impedance of the arcjet was quantified as a function of DC input current over a range of 8 to $11.5 \mathrm{~A}$. The effect of flow rate changes were also investigated over this range of input currents. The dynamic impedance of the arc was quantified by injecting an $\mathrm{AC}$ component onto the DC arc current over the frequency range of 100 $\mathrm{Hz}$ to $100 \mathrm{kHz}$. Effects of variations in flow rate, DC current level, and ripple amplitude on the dynamic impedance were also quantified. The impacts of ripple on thruster performance were assessed with $10 \%$ peak-to-peak ripple amplitude by simultaneous measurement of thrust and dissipated power while varying the ripple frequency over the range of $100 \mathrm{~Hz}$ to $100 \mathrm{kHz}$. Thrust, specific impulse and efficiency were then plotted as functions of ripple frequency. The issues of lifetime and electromagnetic compatibility as a function of ripple amplitude and frequency were not addressed here.

This effort will provide inputs for criteria to determine the ripple acceptable in future power processor designs, which could offer reductions in mass in output filters. The dynamic impedance data are also applicable to power processor controls design in terms of step response and compensation. This will provide more detailed information as to the characteristics of the arcjet and power processor as a system to the power processor designer.

\section{APPARATUS}

\section{Arcjet Thruster}

Two modular thrusters of nearly identical configuration were used. A cutaway schematic of the thruster is shown in Figure 1. The thruster has been described in detail elsewhere. ${ }^{20}$ The constrictor was $0.51 \mathrm{~mm}$ in diameter and $0.25 \mathrm{~mm}$ in length. A $3.18 \mathrm{~mm} 2 \%$ thoriated tungsten welding rod with a conical tip and $30^{\circ}$ half angle was used for the cathode. The anode also was made from the same material and had a $30^{\circ}$ half angle convergent section and a $20^{\circ}$ half angle divergent section. The arc gap was set to $0.58 \mathrm{~mm}$.

\section{Propellant Management}

A 2:1 stoichiometric ratio of hydrogen and nitrogen gas was used as a propellant throughout the testing which simulated the decomposition products of hydrazine monopropellant. The flow rates were maintained using commercially available mass flow controllers.

\section{Power Supply}

A block diagram of the power supply used is presented in Figure 2a. A 150V 15A laboratory supply with a series pass regulator to maintain constant current was used to supply power for the experiment instead of a standard arcjet power processor. A diode in series with the regulator protected it from the high voltage pulse used to start the arcjet. A shunt modulator injected an AC signal of variable frequency and amplitude onto the the regulated DC supply current. Figure $2 \mathrm{~b}$ details the operation of the modulator. The output of the current regulator was represented as $i_{\text {reg }}$ and the current through the modulator $i_{\text {mod }}$, was controlled by the function generator. The arc current $i_{\text {arc }}$ was expressed as:

$$
i_{a x}=i_{\operatorname{reg}}-i_{\bmod }
$$

where $i_{\text {mod }}$ depended on the input from the function generator. The modulator required a $2 \mathrm{~A}$ DC bias current to operate in a linear fashion, thus, the DC component of the arc current, $i_{\mathrm{dc}}$ was lower than the output of the current regulator. This bias current remained constant while the device is in operation. If a sinusoid was input to the modulator the arc current was represented as:

$$
i_{a c}=i_{d c}+i_{a c} \sin (2 \pi f t)
$$

where $i_{d c}$ represents the difference between the regulator current and the DC bias current of the modulator. The amplitude and frequency of $i_{a c}$ were dependent upon the input from the function generator. This approach was used because the frequency response of the current regulator was insufficient to modulate its output directly. A vacuum relay protected the modulator from the high voltage ignition pulse. After the arcjet was started, the vacuum relay was closed and the DC bias on the modulator was applied slowly, avoiding any abrupt changes in arc current.

The arcjet was started with a pulse transformer derived from the $1 \mathrm{~kW}$ arcjet power electronics. Its operation is described in detail elsewhere ${ }^{15,18}$. The pulse was initiated using a pushbutton on the front panel of the equipment rack. An interlock inhibited the operation of the starting circuit if the vacuum relay in the modulator were not open. Coaxial cable was used to supply the current to the arcjet.

\section{Instrumentation}

Arc current was measured using a non-intrusive current probe and a current shunt. The current probe was a commercially available probe with a bandwidth of $\mathrm{DC}$ to $5 \mathrm{MHz}$ which measured both 
DC and AC current components, while the shunt was used to measure DC current only. Arc voltage was measured using an isolated oscilloscope probe, and standard digital multimeters (DMMs). These devices were capable of measuring the $\mathrm{AC}$ and $\mathrm{DC}$ components of the voltage and current. The current probe and shunt were located at the feedthrough to the vacuum chamber and the arc voltage was measured using potential leads mounted to the thruster to minimize the effects of the power cable and connection impedances.

A gain/phase meter was used to measure the relative magnitudes and phases of the $\mathrm{AC}$ arc current and voltage. There are two inputs on the meter. Channel $\mathrm{A}$ is used as a reference and the ratio of the $\mathrm{AC}$ amplitudes of the two channels are displayed as $20 \log (\mathrm{B} / \mathrm{A})$ along with the phase angle between the two channels in degrees. An oscilloscope was used to verify the magnitudes of the arc current components and the frequency of the $\mathrm{AC}$ component was displayed on a frequency counter.

Thrust measurements were made using a flexure displacement thrust stand which was calibrated in situ. This thrust stand is described in detail elsewhere. ${ }^{17}$

Facilities

The experiments were carried out in two facilities $^{20}$. All impedance measurements were done with the thruster mounted in a small bell jar $0.64 \mathrm{~m}$ in length and $0.64 \mathrm{~m}$ in diameter. $A$ single mechanical roughing pump provided $21,000 \mathrm{lpm}$ pumping capacity. Pressures on the order of $100 \mathrm{~Pa}$ were maintained at the maximum propellant flow. All performance measurements were carried out in a vacuum tank $5 \mathrm{~m}$ in length and $1.5 \mathrm{~m}$ in diameter. Four $0.81 \mathrm{~m}$ diameter oil diffusion pumps backed by a lobe type blower and two mechanical roughing pumps maintained the background pressure at approximately $0.05 \mathrm{~Pa}$ at maximum propellant flow.

\section{PROCEDURE}

To quantify the effect of power processor ripple amplitude and frequency on thruster performance it was first necessary to establish a baseline performance level with a DC input current. The thrust level, specific impulse, and efficiency were dependent on the power input to the device, which was determined by the static impedance only for the DC case. As ripple was introduced, the dynamic or AC impedance of the device was included in the equation used to determine the dissipated power. This relation is discussed in depth later. Because of this, the static and dynamic impedances of the arcjet were quantified prior to performance testing. Performance data were taken on only the first of the two arcjets, hereafter referred to as thruster 1 . The second arcjet was referred to as thruster 2 . Dynamic impedance data were taken for both arcjets.

All impedance data were taken in the smaller of the two facilities described previously. Static impedance data were taken using thruster 1 only. The static impedance was measured using a shunt resistor and a DMM to monitor the arc current and another DMM to monitor the arc voltage. Potential taps were added to the thruster and brought out through feedthroughs. The shunt resistor was mounted at the power feedthrough. Both DMMs were battery operated to avoid ground loops.

Flow rates of $4.3 \times 10^{-5}, 4.5 \times 10^{-5}$ and $4.8 \times 10^{-5}$ $\mathrm{kg} / \mathrm{sec}$ were used to investigate the dependence of the dynamic impedance on flow rate. These flow rates are representative of those expected on a NSSK mission. The flow rate to the thruster was set and maintained constant throughout a test. The arcjet was started and allowed to stabilize thermally at $10 \mathrm{~A}$ DC operating current and $4.3 \times 10^{-5} \mathrm{~kg} / \mathrm{sec}$ flow for 30 minutes. The current was then reduced to $8 \mathrm{~A}$ and a 10 minute equilibration period followed. Static voltage and current data were then taken. This process was repeated increasing the current 0.5A DC increments for each data point. Ten minutes were allowed at each setpoint for equilibration.The process continued to the $11.5 \mathrm{~A}$ DC level and was repeated at each flow rate.

To quantify the dynamic impedance it was necessary to inject an AC component onto the DC arc current. This $\mathrm{AC}$ arc current caused an $\mathrm{AC}$ component to appear on the arc voltage. The dynamic impedance of the arcjet was defined as the ratio of this $\mathrm{AC}$ arc voltage to the $\mathrm{AC}$ arc current. $\mathrm{A}$ magnitude and phase were associated with this impedance, and in these data the arc current was used as the reference for the phase angle. The magnitude of the impedance in $\mathrm{dB}$ was given by:

$$
\left|z_{d}\right|=20 \log _{10}\left(\frac{v_{a c}}{i_{a c}}\right)^{[d B]}
$$

and the phase angle $\theta$ was expressed as:

$$
\theta=\tan ^{-1}\left(\frac{\operatorname{Im}\left(z_{d}\right)}{\operatorname{Re}\left(z_{d}\right)}\right) \quad \text { [deg.] }
$$

These data can then be presented in the form of Bode plots and a mathematical description of the following form:

$$
\mathrm{Z}_{\mathrm{d}}(\mathrm{s})=\mathrm{K}_{\mathrm{i}} \frac{\prod_{\mathrm{i}=1}^{n}\left(\mathrm{~s}+\mathrm{q}_{\mathrm{i}}\right)}{\prod_{i=1}^{m}\left(\mathrm{~s}+\mathrm{p}_{\mathrm{i}}\right)}
$$

can be obtained empirically. The zeros of the characteristic equation, $\mathrm{q}_{\mathrm{i}}$, are roots of the numerator, and the poles, $\mathrm{p}_{i}$ are the roots of the denominator. It has been shown that the presence of 
a pole results in a decrease in the magnitude of the characteristic equation of $20 \mathrm{~dB}$ per decade at the corner frequency associated with the pole, and the phase angle contribution is $-90^{\circ}$. A zero will cause the magnitude to increase at a rate of $20 \mathrm{~dB}$ per decade at the comer frequency with a $90^{\circ}$ phase angle contribution. The comer frequencies are determined by the numerical value of the poles and zeros. The theory of system functions and their poles and zeros is explained in detail elsewhere. ${ }^{21}$ The intent of the of the experiments was to map the poles and zeros if present in the frequency range tested.

Thruster 1 was installed in the bell jar as described for the static tests. A current probe was added at the feedthrough to monitor the injected AC arc current component, and an isolated oscilloscope probe was used to monitor the corresponding $\mathrm{AC}$ arc voltage. The mass flow rate was adjusted to the desired level and the arcjet started with the DC arc current level set to $10 \mathrm{~A}$. This DC current level was maintained throughout the testing of thruster 1 . A 30 minute equilibration period followed. The output of the current regulator was increased to $12 \mathrm{ADC}$ and the modulator started. The modulator DC bias current was adjusted to $2 \mathrm{~A}$, reducing the arc current to $10 \mathrm{~A}$. The function generator was adjusted to a frequency of $100 \mathrm{~Hz}$ and the amplitude set so that the modulator injected a $1 A_{p-p}$ sinusoidal current component, an $A C$ current level was that was maintained throughout each test.

The output of the current probe amplifier was set for $\mathrm{AC}$ coupling and input to the gain phase meter channel $A$, the oscilloscope, and the frequency counter. The output of the voltage probe amplifier was input to channel B of the gain/phase meter and the oscilloscope. The gain/phase meter was set to display the ratio of the amplitudes $\mathrm{B} / \mathrm{A}$ and the phase angle of channel $B$ with respect to $A$. The gains of the instrumentation amplifiers were set such that the ratio displayed was $20 \log _{10}\left(\mathrm{v}_{\mathrm{ac}} / \mathrm{i}_{\mathrm{ac}}\right)$. With this configuration the magnitude and phase of the dynamic impedance were read directly. The frequency was then varied in steps of one octave within each decade from $100 \mathrm{~Hz}$ to $100 \mathrm{kHz}$, verifying the ripple frequency with the frequency counter. A five minute equilibration period was allowed following each change in frequency in early tests but was found to be unnecessary.

The procedure was repeated at all flow rates. To quantify the repeatability of the data this test matrix was repeated three times. Attempts to obtain data at higher frequencies were made but the data were found to be unreliable due to the inductance of the power leads in the bell jar.

This procedure was repeated for thruster 2 with the following additions. The DC current level was reduced to $8 \mathrm{ADC}$ and data were taken at $10 \%$ ripple amplitude for the three flow rates to determine the effect of DC current level on the dynamic impedance. Three ripple amplitudes were also used at the $10 \mathrm{ADC}$ level to investigate the linearity of the impedance. The ripple was varied in discrete steps from 8 to $12 \%$.

For performance measurements thruster 1 was installed on a flexure thrust stand in the larger vacuum facility. Calibration and operation of the thrust stand are outlined in detail elsewhere. ${ }^{17} \mathrm{To}$ measure the arc current, the current probe was installed near the vacuum feedthrough along with a standard $100 \mathrm{mV} / 10 \mathrm{~A}$ shunt. The arc voltage in this case was measured at the vacuum feedthrough using a DMM and the isolated oscilloscope probe. The DC current level was maintained at $10 \mathrm{ADC}$ throughout the performance tests, and the ripple amplitude was set at $10 \%$. The arcjet was started at the lower flow rate and allowed to run for 30 minutes at the 10 ADC current level. Thrust measurements were taken at the DC operating point and used as a baseline for comparison to the measurements with ripple. The procedure from this point is identical to that of the dynamic impedance measurements, and these data were taken in tandem with the thrust measurements.

To ensure the accuracy of the impedance data, the

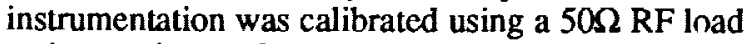
resistor prior to the tests. The gain of each of the instrumentation amplifiers was set so that the gain/phase meter read the impedance magnitude directly in $\mathrm{dB}$. The impedance of the resistor was measured to be $50.5 \Omega$. It was assumed that the imaginary component of the load impedance was negligible in the frequency range of interest, therefore, the dynamic impedance of the device should have a magnitude of $34.1 \mathrm{~dB}(20 \log (50.5))$ and a phase angle of 0 degrees from $100 \mathrm{~Hz}$ to $100 \mathrm{kHz}$. Since the device is purely resistive, the dynamic and static impedances are identical. Any deviations from the $50.5 \mathrm{ohm}$ impedance were assumed to result from gain errors and phase lags in the amplifiers. The resulting errors were small, but all data taken using the thruster were corrected accordingly.

\section{RESULTS AND DISCUSSION}

For a given configuration the performance of the arcjet was dependent on the mass flow rate and the power dissipated in the device. To properly compute dissipated power, it was necessary to quantify the arcjet impedance. For this reason, the impedance data are presented first, followed by the performance data.

\section{Static Impedance}

The static impedance data for thruster 1 are presented in the form of volt-ampere curves in Figure 3. The arc voltage decreases with increasing current, and this behavior is typical for high pressure 
arcs as described in detail elsewhere. ${ }^{22}$ An increase in the mass flow rate resulted in an increase in the static impedance. This was due to the associated increase in arc chamber pressure and a reduction in the mean free path between propellant molecules. The shortened free path length resulted in an increase in the collision rate between particles, and more energy was needed to maintain the necessary ionization levels at a given current. Thus, a larger electric field was required, increasing the arc voltage. This phenomenon is described in detail elsewhere. ${ }^{23}$

\section{Dynamic Impedance Magnitude}

The magnitude of the dynamic impedance for thruster 1 is presented in Figure 4a, and the phase data in Figure $4 \mathrm{~b}$. The DC arc current was 10A and the $\mathrm{AC}$ component had an amplitude of $1 \mathrm{~A}_{\mathrm{p}-\mathrm{p}}$. For a given flow rate it can be seen that the magnitude of the impedance remains relatively constant from $100 \mathrm{~Hz}$ to $10 \mathrm{kHz}$, with a $2 \mathrm{~dB}$ decrease in magnitude from $10 \mathrm{kHz}$ to $100 \mathrm{kHz}$. There was some indication of a possible minima in the impedance magnitude at $80 \mathrm{kHz}$. In general, as the flow rate increased the magnitude of the dynamic impedance increased. This increase was not linear over the frequency range tested, but varied from approximately 0.2 to $0.5 \mathrm{~dB}$ from the $4.3 \times 10^{-5}$ to the $4.8 \times 10^{-5} \mathrm{~kg} / \mathrm{sec}$ mass flow rate.

\section{Dynamic Impedance Phase Angle}

The phase angle of the impedance was $190^{\circ}$ at $100 \mathrm{~Hz}$, and remained constant, within $10^{\circ}$, to 10 $\mathrm{kHz}$, where the phase angle began to decrease. The phase angle remained greater than $90^{\circ}$ for the range of frequencies tested, therefore, the dynamic impedance had a negative real component for this frequency range. This indicated that the $V / I$ characteristic for this frequency range maintained a negative slope. From these data it appears that the flow rate had little effect on the phase angle of the impedance. A discontinuity in the magnitude and phase data occurred at $1 \mathrm{kHz}$. This was an experimental artifact traceable to the input filters on the gain phase meter. A $1 \mathrm{kHz}$ low pass filter was used for frequencies below $1 \mathrm{kHz}$. For higher frequencies a $100 \mathrm{kHz}$ filter was used. This filter was not responsible for the minima in the impedance magnitude at $80 \mathrm{kHz}$, as the tests on the RF load verified flat response in this region.

\section{Data Repeatability}

As shown in Figures $5 \mathrm{a}$ and $5 \mathrm{~b}$, the dynamic impedance tests on tests on thruster 2 yielded results similar to those obtained with thruster 1 . The magnitude of the dynamic impedance of the two thrusters agreed to within $1 \mathrm{~dB}$ and the phase angle to within 5 degrees.

\section{Mathematical Model}

From these data, no poles or zeros can be mapped because the magnitude of the impedance remained nearly constant. However, the phase angle of the dynamic impedance decreased as the ripple frequency increased. This phenomenon can be characterized by a transportation lag, which is mathematically described as follows:

$$
z_{d}(s)=e^{-s \tau}
$$

where $s=j 2 \pi f$, and $\tau$ is the transportation lag in seconds. This function has a magnitude of 1 because:

$|\cos (2 \pi \mathrm{f} \tau)-j \sin (2 \pi \mathrm{f} \tau)|=1 \quad(7)$ The phase angle is 0 for low values of $f$ and becomes more negative as $f$ increases ${ }^{23}$. The magnitude of the dynamic impedance was greater than 1 however, and this can be accounted for by introducing a gain constant $\mathrm{C}$. The absolute value of the gain constant can be obtained from the dynamic impedance data for a given flow rate. The magnitude of the dynamic impedance was found using equation 3 , thus, the value of the gain constant is:

$$
\mathrm{C}=10^{\frac{\left|z_{\mathrm{d}}\right|[\mathrm{B}]}{\mathrm{D}}}
$$

Where $\left|z_{d}\right|$ was taken from the data of Figure 4a. The phase angle of the arc impedance was $180^{\circ}$ for low frequencies and this can be accounted for by multiplying equation 6 by -1 , which introduces a 180 degree phase shift for low frequencies. The phase angle will decrease as frequency increases depending on the constant $\tau$ in equation 6 can be estimated from the phase data of Figure $4 \mathrm{~b}$ and was found to be on the order of $1.5 \times 10^{-6}$ seconds. Since the phase data showed no significant dependence on flow rate, this value of $\tau$ can be used for all flow rates tested. The gain constant $\mathrm{C}$, however, is dependent on flow rate. Typical values were on the order of 3.76 for the $4.8 \times 10^{-5} \mathrm{~kg} / \mathrm{sec}$ flow. The dynamic impedance can therefore be approximately expressed as

$$
Z_{d}(s)=-C e^{-\left(1.5 \times 10^{-6}\right) s}
$$

for the frequency range of $100 \mathrm{~Hz}$ to $100 \mathrm{kHz}$. Figures $6 \mathrm{a}$ and $6 \mathrm{~b}$ compare the measured dynamic impedance magnitude and phase with those predicted by equation 9 . The data compares favorably with the calculated values. The maximum error of $2 \mathrm{~dB}$ occurs at $100 \mathrm{kHz}$. These values for the dynamic impedance magnitude were higher than those predicted by the static V/I curves, which were on the order of $6 \mathrm{~dB}$. This value was obtained in the following manner. When a $1 \mathrm{~A}$ peak-to-peak $\mathrm{AC}$ current component was superimposed on the $D C$ arc current, the arc current had a maximum value of $10.5 \mathrm{~A}$ and a minimum value of $9.5 \mathrm{~A}$. The difference between the corresponding arc voltages for these 
current values quantified the dynamic impedance since $\mathrm{Z}=\mathrm{V} / \mathrm{I}$. The magnitudes obtained in the frequency range tested were greater than this expected value. This may indicate the presence of a pole-zero pair at very low frequencies. This is further supported by the $190^{\circ}$ phase shift at $100 \mathrm{~Hz}$. A phase angle of only $180^{\circ}$ is expected from the static curves. Further work is necessary to investigate this phenomenon. From these data, there is no indication that the regulator step response need be changed.

\section{Linearity}

Thruster 2 was used to investigate the linearity of the dynamic impedance. If the dynamic impedance was linear, the impedance magnitude should remain constant regardless of the magnitude of the AC component. Figure 7a presents the magnitude data and Figure $7 \mathrm{~b}$ the phase data for a DC current of $10 \mathrm{~A}$ and $\mathrm{a}$ fixed flow rate. The magnitude of the $\mathrm{AC}$ component was varied from 8,10 and $12 \%$ of the DC level. The magnitude of the dynamic impedance appears to decrease as the magnitude of the $\mathrm{AC}$ component increases. The total deviation over this range of ripple amplitudes is on the order of $.25 \mathrm{~dB}$. The results of the phase angle measurements were similar.

The effect of the DC current level on the dynamic impedance was investigated with arc currents of 8 and 10 amperes respectively. The magnitude of the AC component was maintained at $10 \%$ for the investigation. The static impedance data in Figure 3 show that the slope of the static volt-ampere curve was more negative at 8 than at $10 \mathrm{~A}$. Thus, it was expected that the magnitude of the dynamic impedance at $8 \mathrm{~A}$ would be greater than at the $10 \mathrm{~A}$ point. This indicates that the gain constant $\mathrm{C}$ of equation 9 is also dependent on the DC current level. The impedance magnitude data are presented in Figure 8a. At 8 amperes the magnitude of the dynamic impedance was in fact an average of $4 \mathrm{~dB}$ greater than at the 10 ampere level. The impedance phase data are presented in Figure $8 \mathrm{~b}$. The phase angle for the $8 \mathrm{~A}$ case was virtually identical to the $10 \mathrm{~A}$ case.

\section{Thruster Performance}

The effects of power processor ripple on arcjet performance had not been determined. To quantify these effects, the thrust produced by the arcjet was measured while varying the ripple frequency. For these measurements, the ripple peak-to-peak amplitude was maintained at $10 \%$ of the $D C$ value.

One possible scenario for a degradation in performance was a change in the dissipated power in the arcjet with ripple present when compared to the DC case. This was supported by previous work which demonstrated that the pressure in the arc chamber of the thruster was proportional to the input power, and therefore, thrust and specific impulse were also related to the input power ${ }^{24}$. When calculating the power dissipated in the DC case, only the static impedance characteristics were of interest, thus the power dissipated was simply the product of the DC arc voltage and current. However, when the AC ripple component was superimposed, the dynamic impedance was also considered. If the current input to the arcjet was:

$$
i_{a r c}=i_{d c}+i_{a c} \sin (2 \pi f t)
$$

where $i_{\mathrm{ac}}$ was the amplitude of the ripple, or one half of the peak-to-peak amplitude, then the resulting arc voltage was:

$$
v_{\mathrm{arc}}=\mathrm{v}_{\mathrm{dc}}+\mathrm{v}_{\mathrm{ac}} \sin (2 \pi \mathrm{ft}+\theta)
$$

where $\theta$ was the phase angle between the $A C$ arc voltage current, using the current as the reference. The amplitude of the $\mathrm{AC}$ arc voltage and the phase angle $\theta$ were determined from the dynamic impedance data presented in Figures $4 a$ and $b$. The dynamic impedance magnitude data of Figure 4a were measured by the gain/phase meter as the ratio of the amplitudes of the AC arc voltage over the $\mathrm{AC}$ arc current, represented by equation 3 . Since the amplitude of the AC arc current was 1A peak-topeak, the AC voltage peak-to-peak amplitude was exactly equal to the dynamic impedance in ohms, which could be calculated using equation 8 . This peak-to-peak amplitude was then divided by 2 to determine the actual amplitude of the $\mathrm{AC}$ arc voltage. The phase angle $\theta$ was taken directly from the data of Figure $4 \mathrm{~b}$, and the RMS power dissipation was then calculated with the relation:

$$
p_{\text {rms }}=v_{d c} i_{d c}+\frac{v_{a c} i_{a c}}{2} \cos (\theta)
$$

Since the dynamic impedance had a magnitude and phase, a real and complex or imaginary component were associated with the impedance. If the value of the real component of the impedance was negative, the value of $\cos \theta$ was also negative. This was the case for the entire frequency range of this experiment since $90^{\circ}<\theta<270^{\circ}$ as shown in Figure $4 \mathrm{~b}$. The right hand term of equation 12 then constituted a loss when compared to the pure DC case, since the DC current level and DC arc voltage remained constant. The magnitude of the loss depended on the magnitude of the AC V-I product and the value of the phase angle.

The experiment apparatus allowed the simultaneous measurement of the thrust, $\mathrm{AC}$ and $D C$ arc voltages and currents, and the flow rate. Thus, the thrust and power dissipated could be continuously monitored while the ripple frequency 
was varied. The impedance data taken while on the thrust stand correlated with the impedance data shown in Figures $4 a$ and $4 b$, taken in a separate facility. In the frequency range tested, the value for $\theta$ remained greater than $90^{\circ}$, thus the value of the right hand term of equation 12 remained negative throughout. However, the magnitude of the $V^{*} I$ product for the AC component was small, in this case less than 5 watts, which is less than $1 \%$ of the total power.

The thruster was operated at a fixed flow rate with a DC current level of $10 \mathrm{~A}$ with an $\mathrm{AC}$ component of $1 A_{p}$-p. Figure 9 presents the thrust data for three flow rates. The DC thrust levels for each flow rate are represented by a horizontal line. The thrust level remained constant throughout the frequency range tested, therefore, the specific impulse also remained constant. The overall efficiency is presented in Figure 10. There are minor deviations in the efficiency, but these are more likely due to the propagation of measurement errors in the calculations. The changes in performance were insignificant at all frequencies tested, as was expected from the power calculations.

\section{CONCLUSIONS}

The interface between a $1 \mathrm{~kW}$ class arcjet and future power processors was characterized by determining the impacts of power supply output characteristics on arcjet performance and by characterizing the arcjet as a static and dynamic electrical load. The impacts of power supply ripple on arcjet performance were assessed with a ripple amplitude of $10 \%$ peak-to-peak of the DC current level.

Characterization of the arcjet as an electrical load required the measurement of the static and dynamic impedances of the arc. The static impedance data show that the DC operating voltage of the arcjet is a function of the input current and flow rate. The arc voltage decreases with increasing current and increases with flow rate. A curve fit of the $V / I$ data results in an equation that fairly accurately describes the static impedance for a given flow rate, provided that the cathode has been run for a sufficient time to render the effect of further erosion negligible. Variations in the static impedance from thruster to thruster were not characterized.

The dynamic impedance also exhibits similar trends with flow rate. Initially it was intended to assign poles and zeros to the impedance using frequency response methods. However, from these data it was difficult to assign poles and zeros to the dynamic impedance because the magnitude remained constant to within $2 \mathrm{~dB}$ across the $100 \mathrm{~Hz}$ to 100 $\mathrm{kHz}$ range tested. A phase shift of approximately $180^{\circ}$ was noted at low frequencies, but decreased at frequencies above $10 \mathrm{kHz}$. This is representative of a transportation lag in the arc column on the order of $1.5 \mu$ s. The transportation lag was multiplied by a negative gain constant to account for the $180^{\circ}$ phase shift at low frequencies. The value of the gain constant was found to be dependent on flow rate and the DC current level. Thus, for the frequency range in tested the dynamic impedance of the arc can be represented as

$$
z_{d}(s)=-C e^{-\left(15 \times 10^{-6}\right) s}
$$

A typical value for $C$ was found to be on the order of 3.76 for a $10 \mathrm{~A}$ DC current level. This value increased as the DC current level decreased for a given ripple amplitude of $10 \%$ peak-to-peak.

This magnitude, however, is greater than that expected from the static curves. This may indicate presence of a pole-zero pair at a very low frequency. Further work is necessary to investigate this phenomenon. From these data, there was no indication that the step response of the power processor regulator should be changed. These data were taken with two thrusters of nearly identical configuration and the data compared favorably, indicating that these data were transportable between thrusters.

The effects of ripple on arcjet performance were assessed by measuring DC performance levels at various flow rates to provide a baseline for comparison to thruster performance with power supply ripple present. An AC component of constant amplitude and variable frequency was then injected to simulate power supply ripple. Thrust and input power were measured simultaneously while the ripple frequency was varied from $100 \mathrm{~Hz}$ to 100 $\mathbf{k H z}$. The dynamic impedance of the arcjet caused the dissipated power in the arcjet to decrease slightly due to the phase angle associated with the dynamic impedance which was greater than $90^{\circ}$. The total reduction in power was less than $1 \%$, thus, the $\mathrm{AC}$ component was found to have no measurable effect on thrust, specific impulse or overall efficiency over the frequency range tested. This indicates that present power supply designs, with output ripple currents on the order of $10 \%$ peak-to-peak, are not compromising overall system performance. The impact of ripple on thruster lifetime was not assessed in this work, however, past experience indicates that this is not an issue for mission lifetimes of 1000 hours.

\section{REFERENCES}

1. John, R.R., Connors, J.F., and Bennet, S., "Thirty Day Endurance Test of a $30 \mathrm{~kW}$ Arcjet Engine", AIAA Paper 63-274, June 1963. 
2. John, R.R., "Thirty Kilowatt Plasmajet RocketEngine Development," RAD-TR-64-6, Avco Corp. , Wilmington, MA, NASA CR-54044, 1964

3. Todd J.P., and Sheets, R.E., "Development of a Regeneratively Cooled 30-kW Arcjet Engine,"

AIAA Joumal, Vol. 3, No. 1, Jan. 1965, pp. 122126.

4. Todd, J.P., "30 kW Arcjet Thruster Research," APL-TDR-64-58, Gianni Scientific Corp., Santa Ana, CA, Mar. 1964. (Avail. NTIS, AD-601534.)

5. Ducati, A.C., Humpal, H., Metzler, J., Muehlberger, E., Todd, J.P., and Waltzer, H., "1kW Arcjet-Engine System-Performance Test," Joumal of Spacecraft and Rockets, Vol. 1, No. 3, May-June 1964, pp. 327-332.

6. Mc Caughey, O.J., Geideman, W.A., Jr., amd Mueller, K., "Research and Development of a $2 \mathrm{~kW}$ Arc-Jet Thruster," GRC-1646, Plasmadyne Corp., Santa Ana, CA, NASA CR-54035, 1963.

7. Shepard, C.E., and Watson, V.R., "Performance of a Constricted-Arc Discharge in a Supersonic Nozzle," Physico-Chemical Diagnostics of Plasmas, T.P. Anderson, R.W. Springer, and R.C. Warder, Jr., eds., Northwestern University Press, 1964, pp. 261-272. (AIAA Paper 63-380).

8. Wallner, L.E., and Csika, J. Jr., "Arc-Jet Thrustor for Space Propulsion," NASA TN D-2868, 1965.

9. Nakanishi, S., "Experimental performance of a 1 Kilowatt Arcjet Thruster," AIAA Paper 85-2033, Oct. 1985. (NASA TM-87131.)

10. Curran, F.M., and Nakanishi, S., "Low Power dc Arcject Operation with Hydrogen/Nitrogen Propellant Mixtures," AIAA Paper 86-1505, June 1986. (NASA TM-87279)

11. Hardy, T.L., and Curran, F.M., "Low Power dc Arcjet Operation with Hydrogen/Nitrogen/ Ammonia Mixtures," AIAA Paper 87-1948, June 1987. (NASA TM-89876)

12. Knowles, S.C., Smith, W.W., Curran, F.M., and Haag, T.W., "Performance Characterization of a Low Power Hydrazine Arcjet," AIAA Paper 87. 1057, May 1987.

13. Knowles, S.C., "Arcjet Thruster Research and Technology, Phase I, Final Report," 87-R-1175, Rocket Research Co., Redmond, WA, Sept. 1987.
14. Simon, M.A., Knowles, S.C., Curran F.M., and Hardy, T.L., "Low Power Arcjet Life Issues," AIAA Paper 87-1059, May 1987.

15. Gruber, R.P., "Power Electronics for a 1-kW Arcjet Thruster," AIAA Paper 86-1507, June 1986. (NASA TM-87340)

16. Curran, F.M., and Haag T.W., "Arcjet Component Conditions Through a Multistart Test," AIAA Paper 87-1060, May 1987. (NASA TM89857)

17. Haag, T.W., and Curran, F.M., "Arcjet Starting Reliability: A Multistart Test on Hydrogen/ Nitrogen Mixtures," AIAA Paper 87-1061, May 1987. (NASA TM-89867)

18. Sarmiento, C.J., and Gruber, R.P., "Low Power Arcjet Thruster Pulse Ignition," AIAA Paper 871951, July 1987. (NASA TM-100123)

19. Knowles, S.C.,Arcjet Thruster Research and Technology Phase II., NASA CR 182276, 1990, (To be published)

20. Curran, F.M., and Haag, T.W., "An Extended Life and Performance Test of a Low Power Arcjet," AIAA Paper 88-3106, July 1988. (NASA TM100942)

21. Gupta, S.C., and Hasdorff, L., Fundamentals of Automatic Control, Robert E. Krieger Publishing Co., Florida, 1983

22. Cobine, J.D., Gaseous Conductors, Dover Publications Inc., New York, 1941

23. Ogata, K., Modem Control Engineering. Prentice-Hall Inc., Englewood Cliffs, New Jersey, 1970

24. Curran, F.M., "An Experimental Study of Energy Loss Mechanisms and Efficiency Considerations in the Low Power dc Arcjet," AIAA Paper 85-2017, September 1985. (NASA TM87123) 


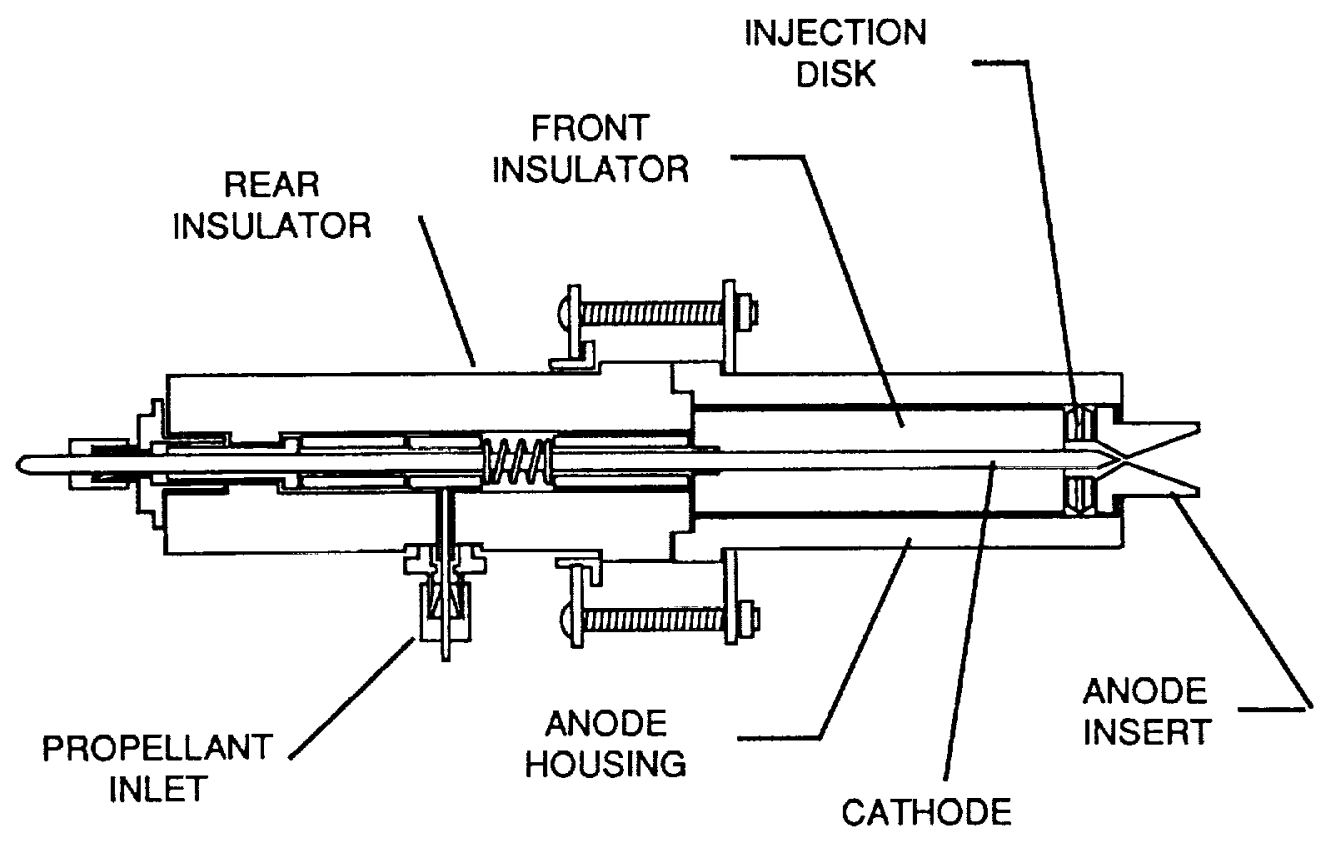

Figure 1. - Cutaway view of arcjet thruster.

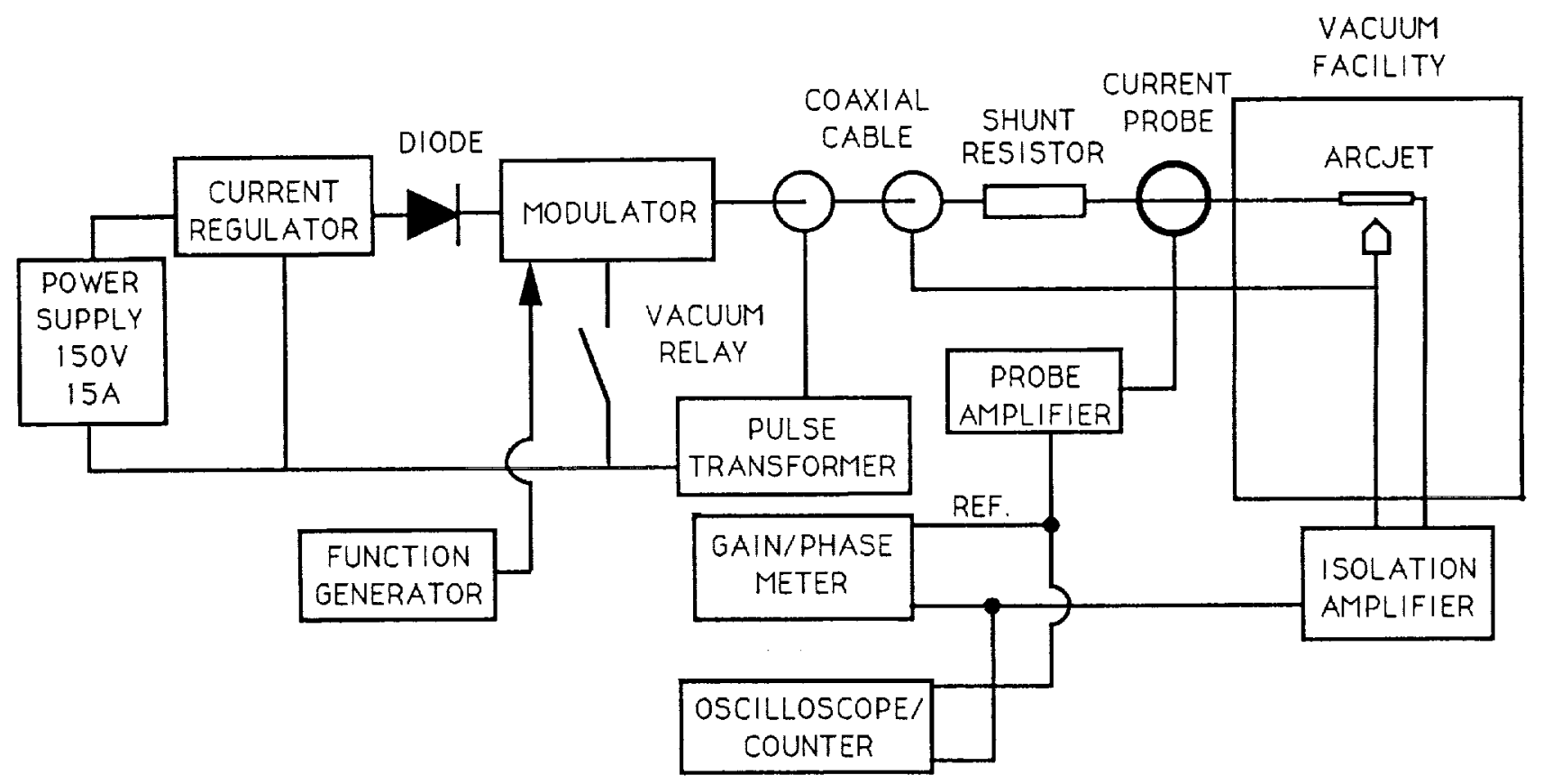

Figure 2a. - Apparatus block diagram. 


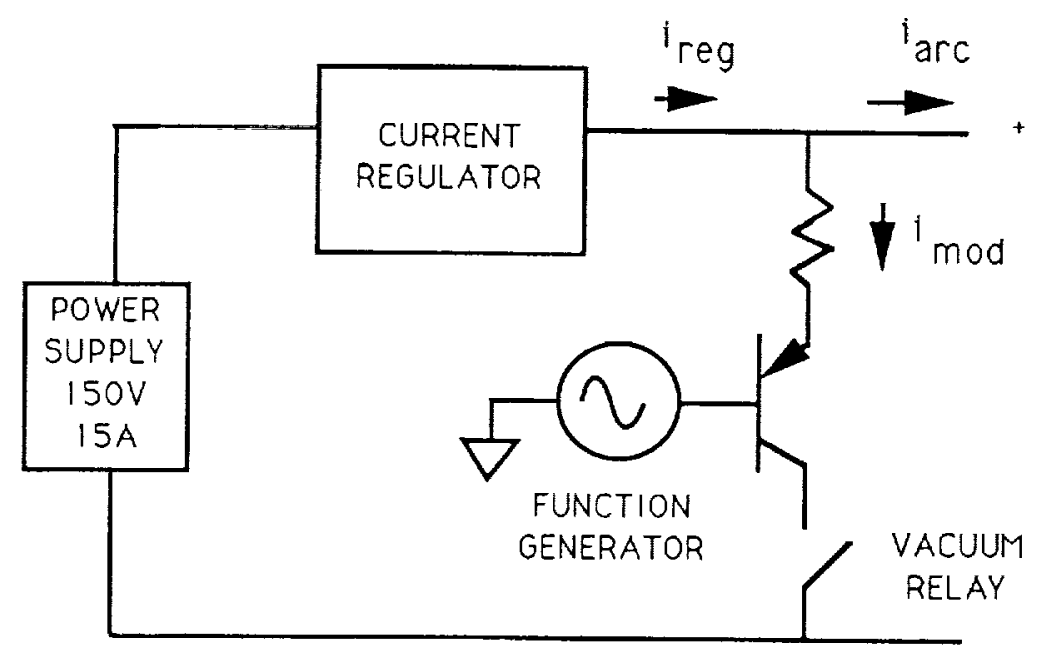

Figure 2b. - Regulator/Modulator operation.

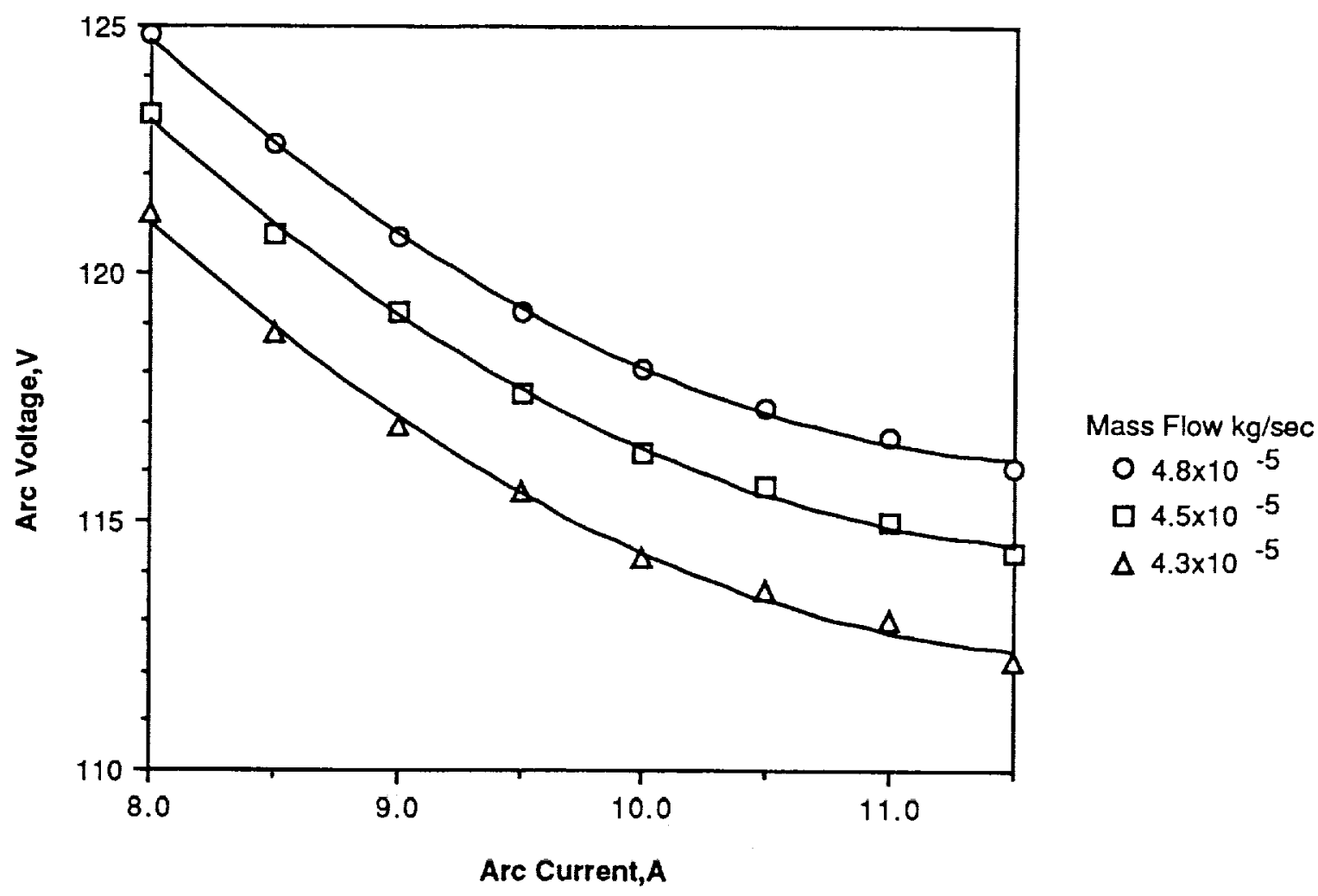

Figure 3. - Static Volt/Ampere characteristics for various flow rates, Thruster 1. 


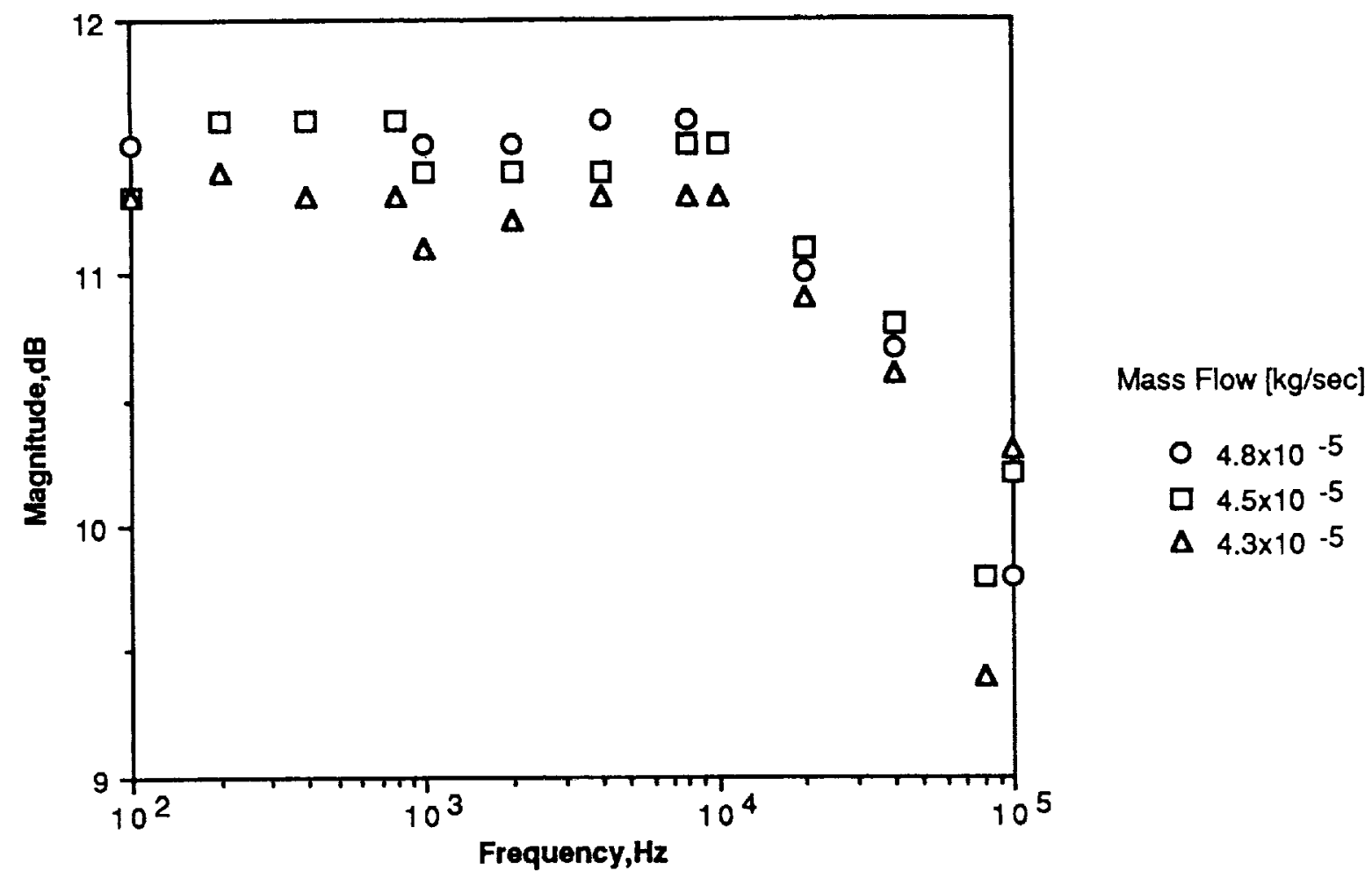

Figure 4a. - Dynamic impedance magnitude vs. frequency at various flow rates, thruster 1.

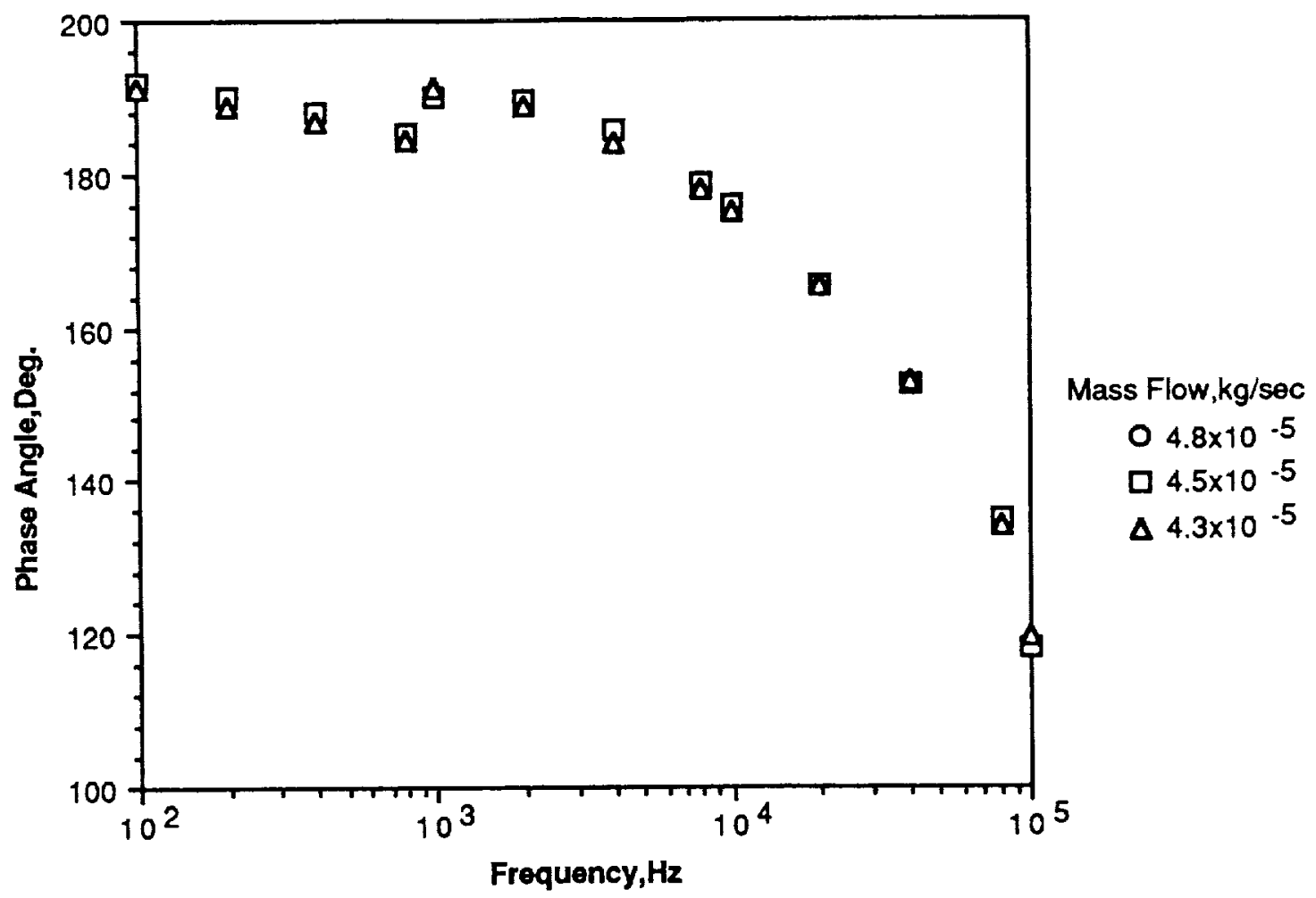

Figure $4 b$. - Dynamic impedance phase angle vs. frequency at various flow rates, thruster 1. 


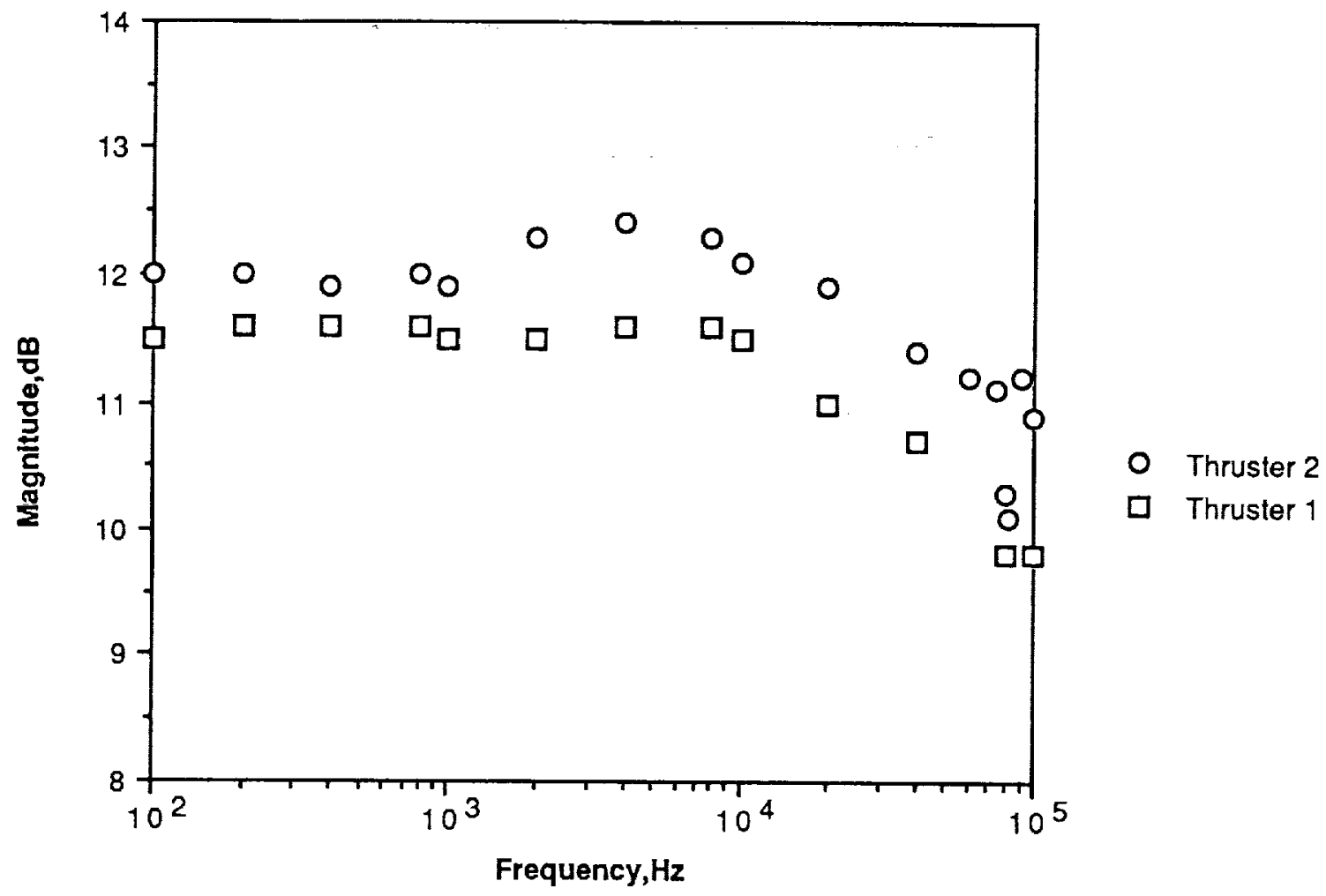

Figure 5a. - Comparison of dynamic impedance magnitude, thrusters 1 and 2, flow rate and DC current fixed.

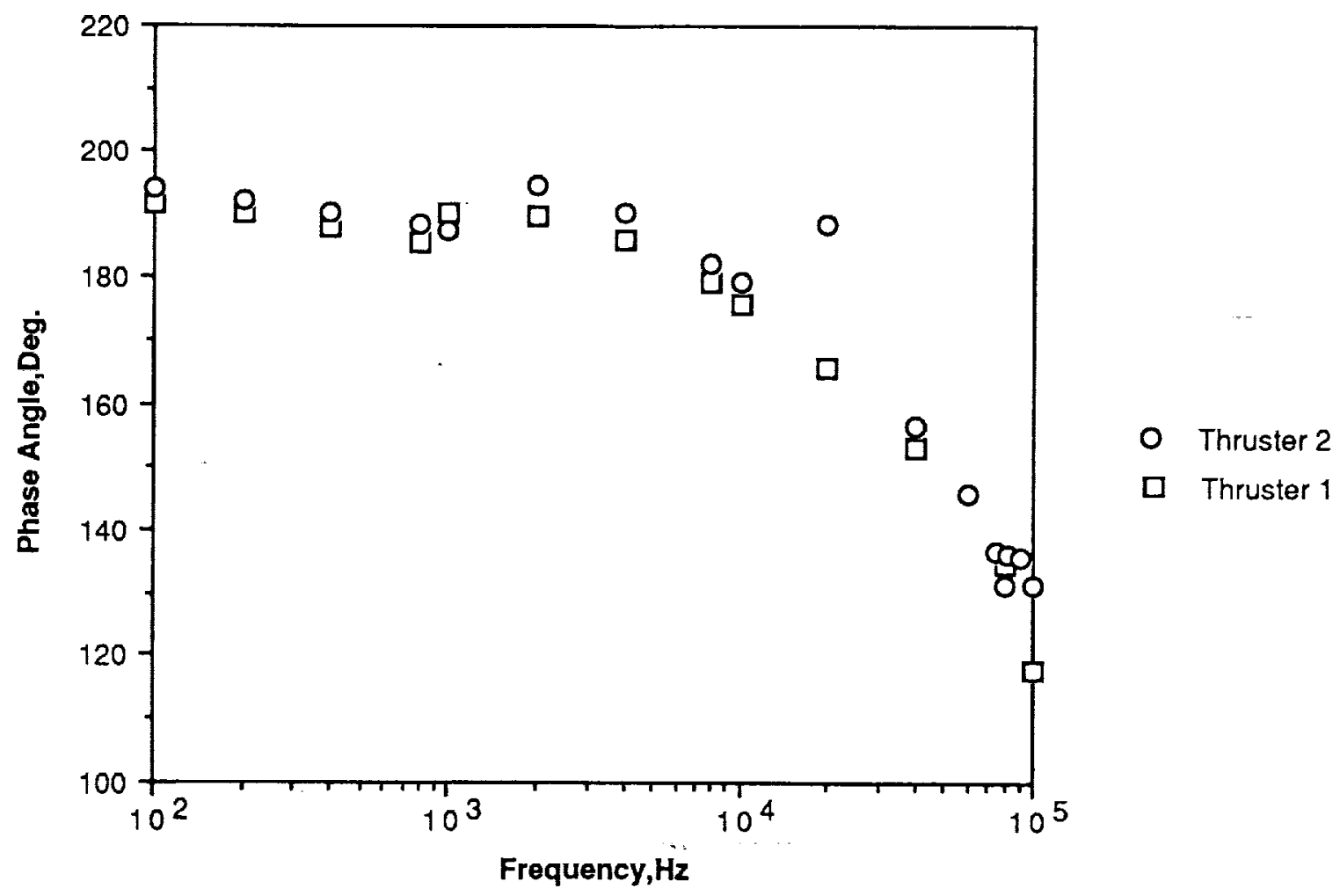

Figure 5b. - Comparison of dynamic impedance phase angle, thrusters 1 and 2 , flow rate and DC currrent fixed. 


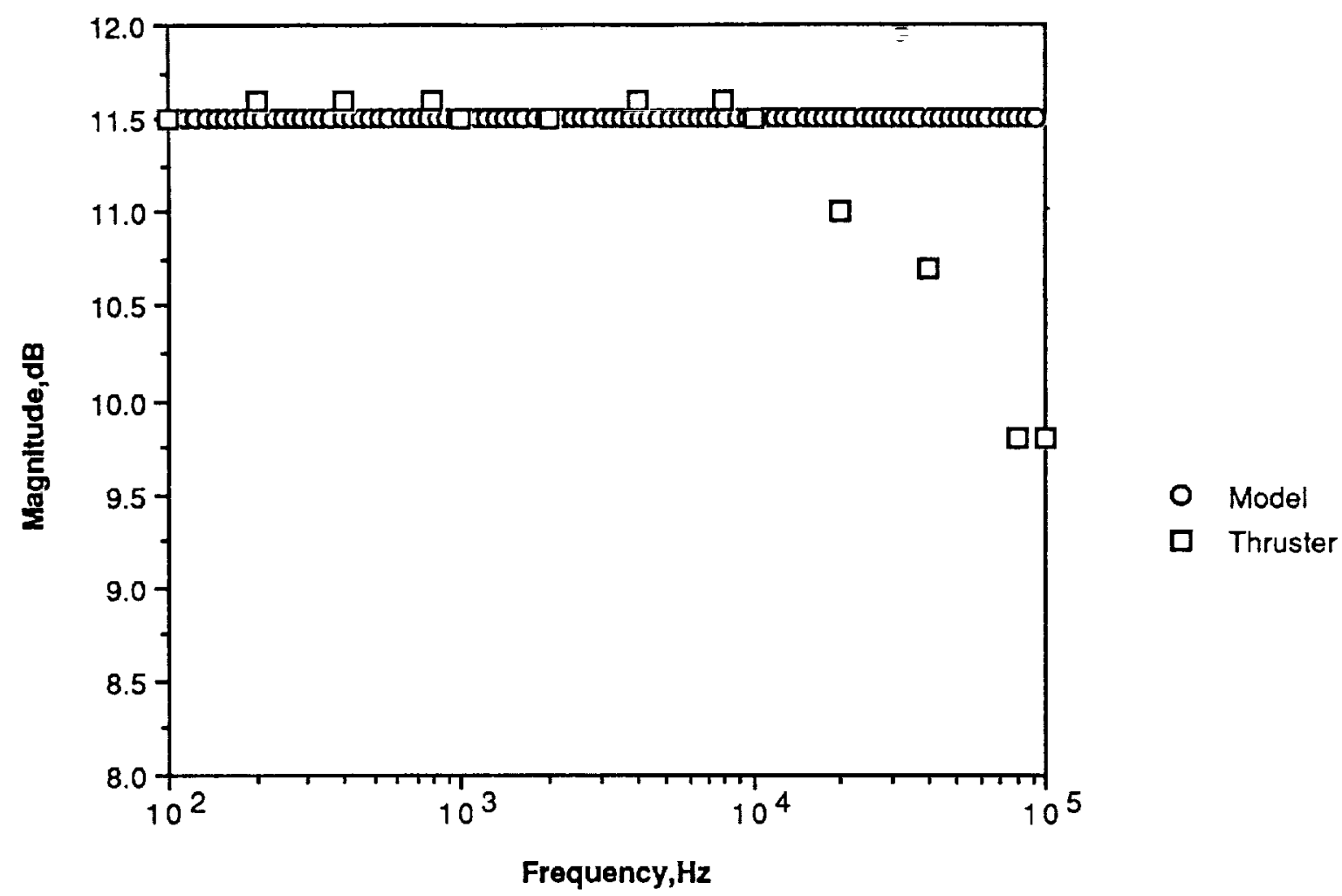

Figure 6a. - Comparison of dynamic impedance magnitude predicted by model and thruster data, $.00048 \mathrm{~kg} / \mathrm{sec}$ flow rate.

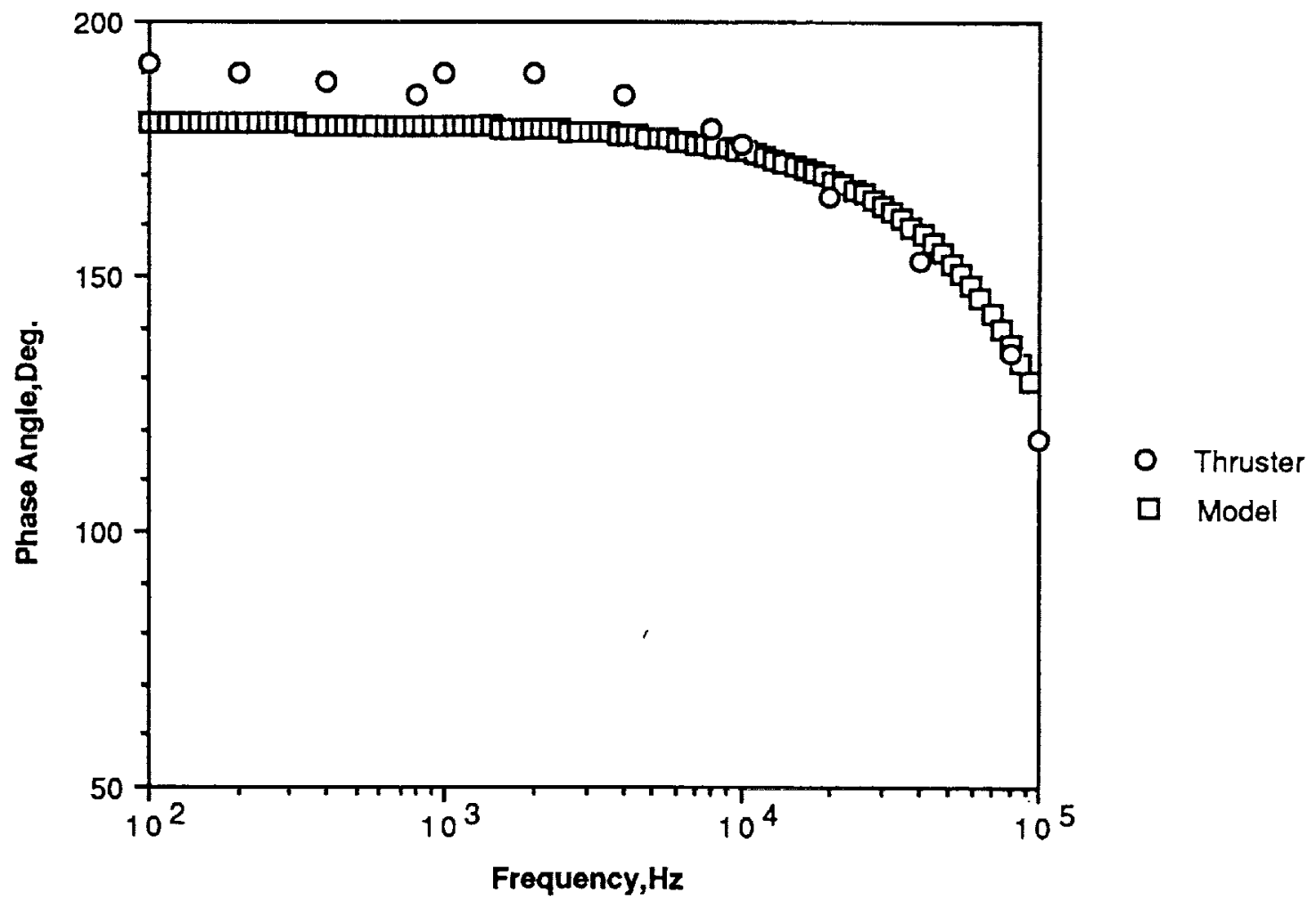

Figure $6 \mathrm{~b}$. - Comparison of impedance phase angle predicted by model and thruster data, $.00048 \mathrm{~kg} / \mathrm{sec}$ flow rate. 


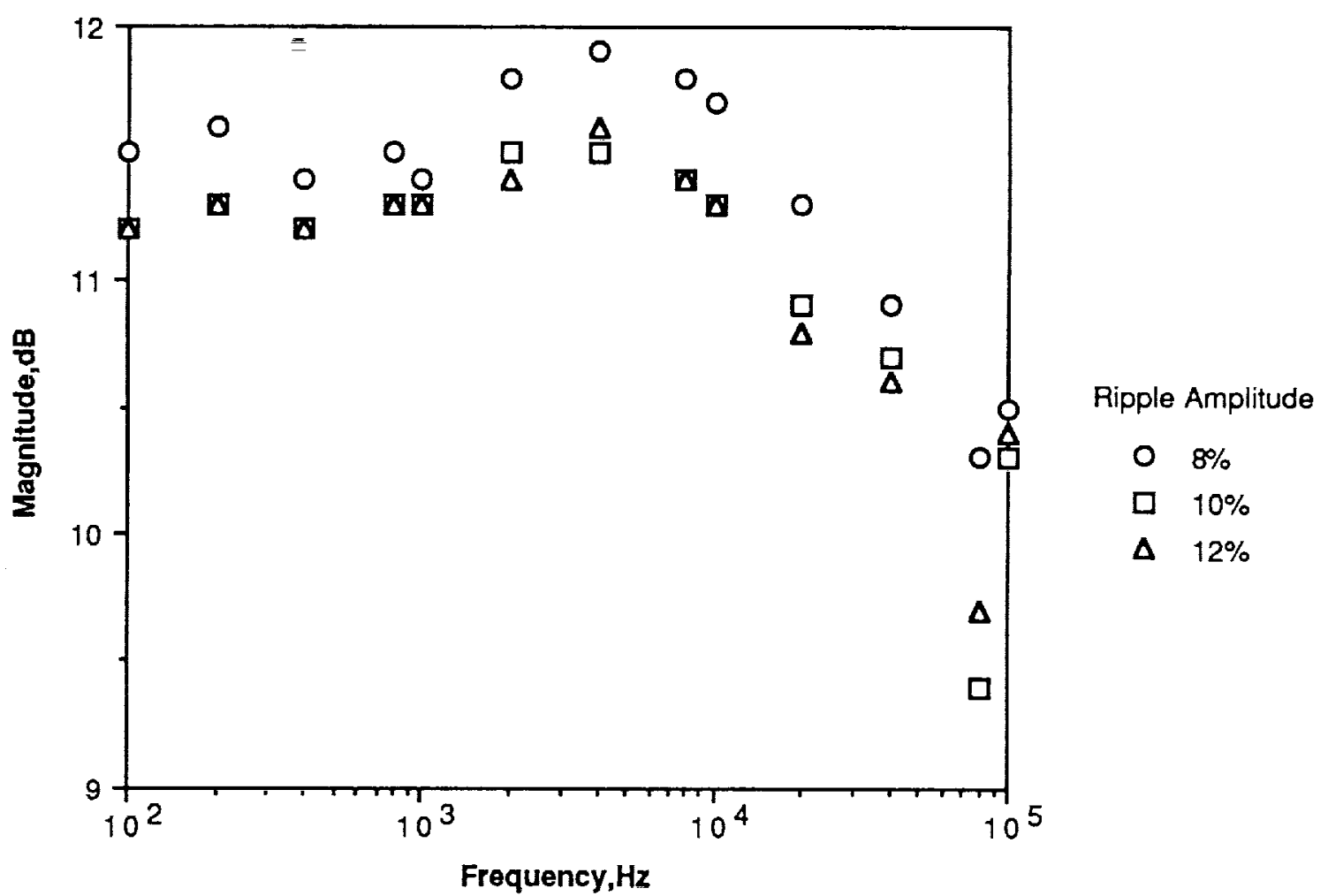

Figure 7a. - Dynamic impedance magnitude vs. frequency for various peak-to-peak ripple amplitudes, thruster 2.

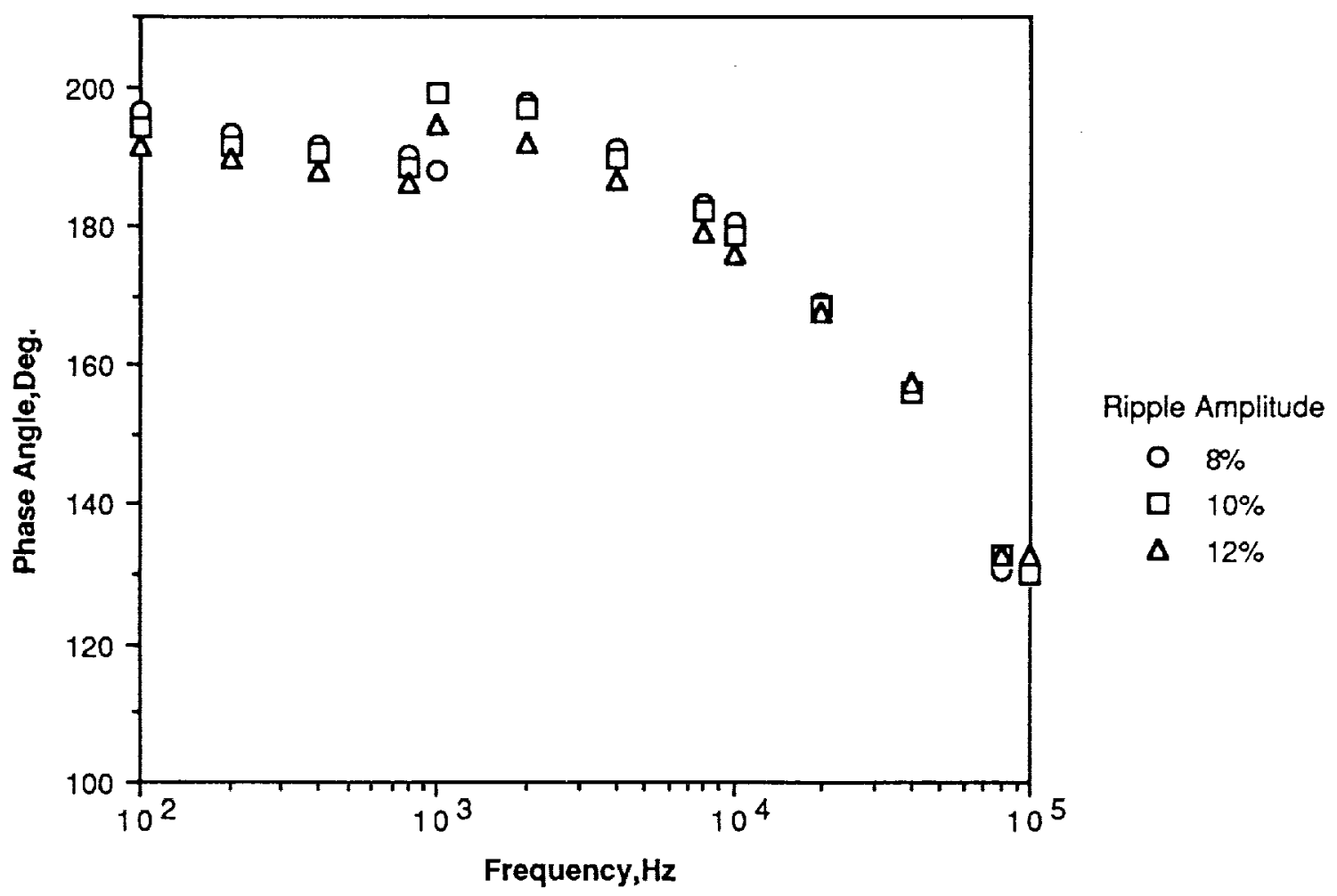

Figure 7b. - Dynamic impedance phase angle vs. frequency for various ripple amplitudes, thruster 2. 


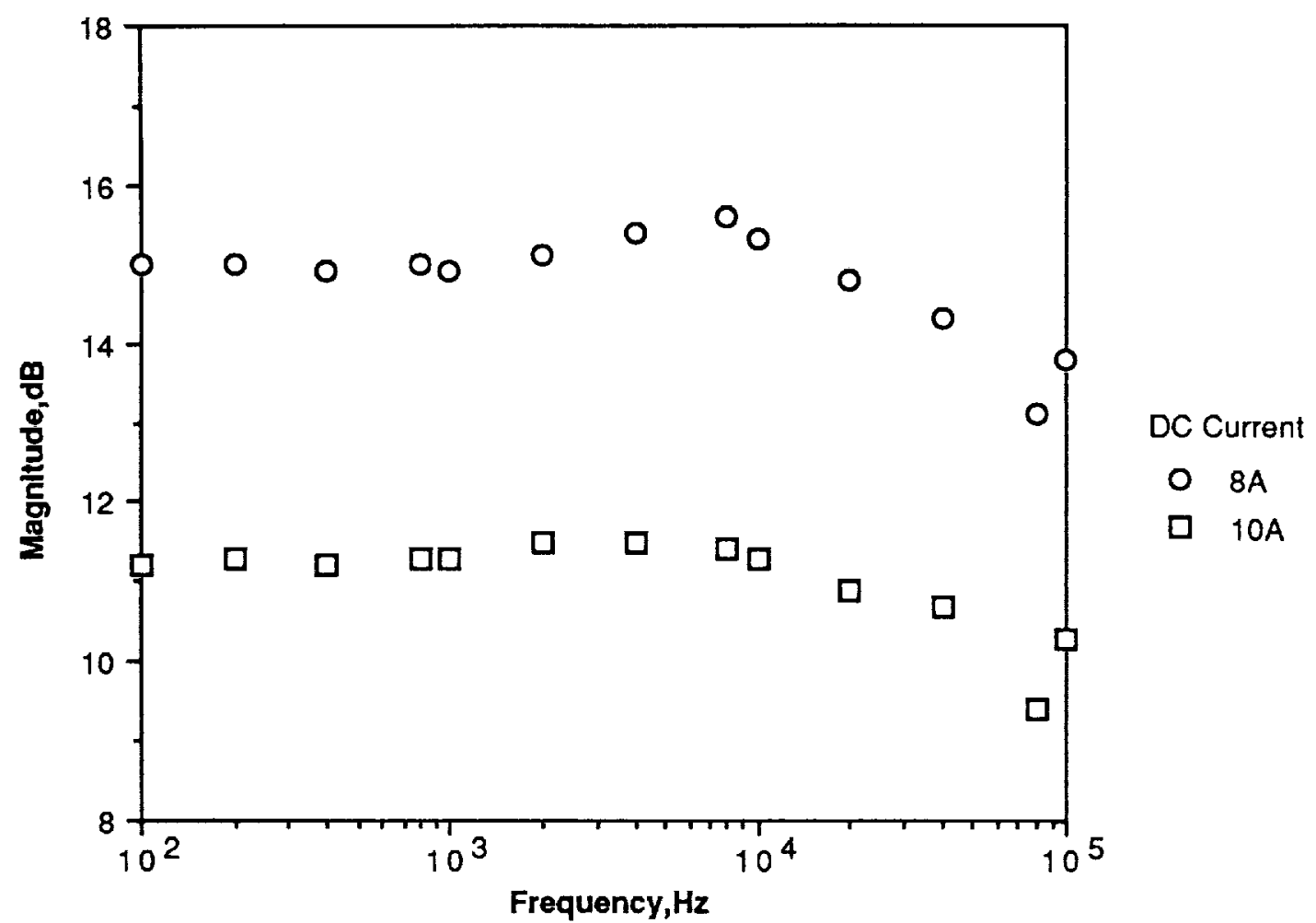

Figure 8a. - Dynamic impedance magnitude vs. frequency for different DC current levels, thruster 2.

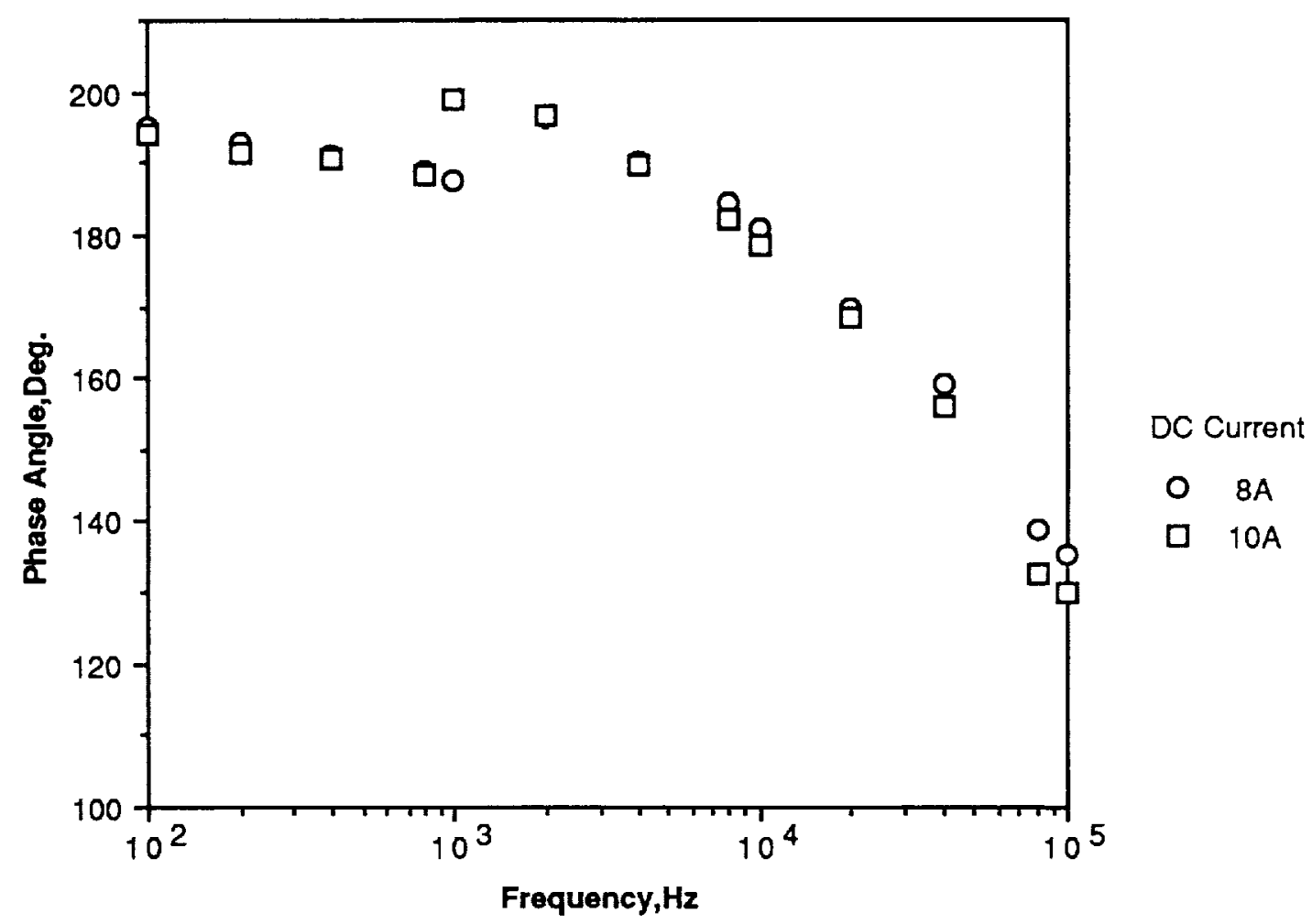

Figure 8b. - Dynamic impedance phase angle vs. frequency for different DC current levels, thruster 2. 


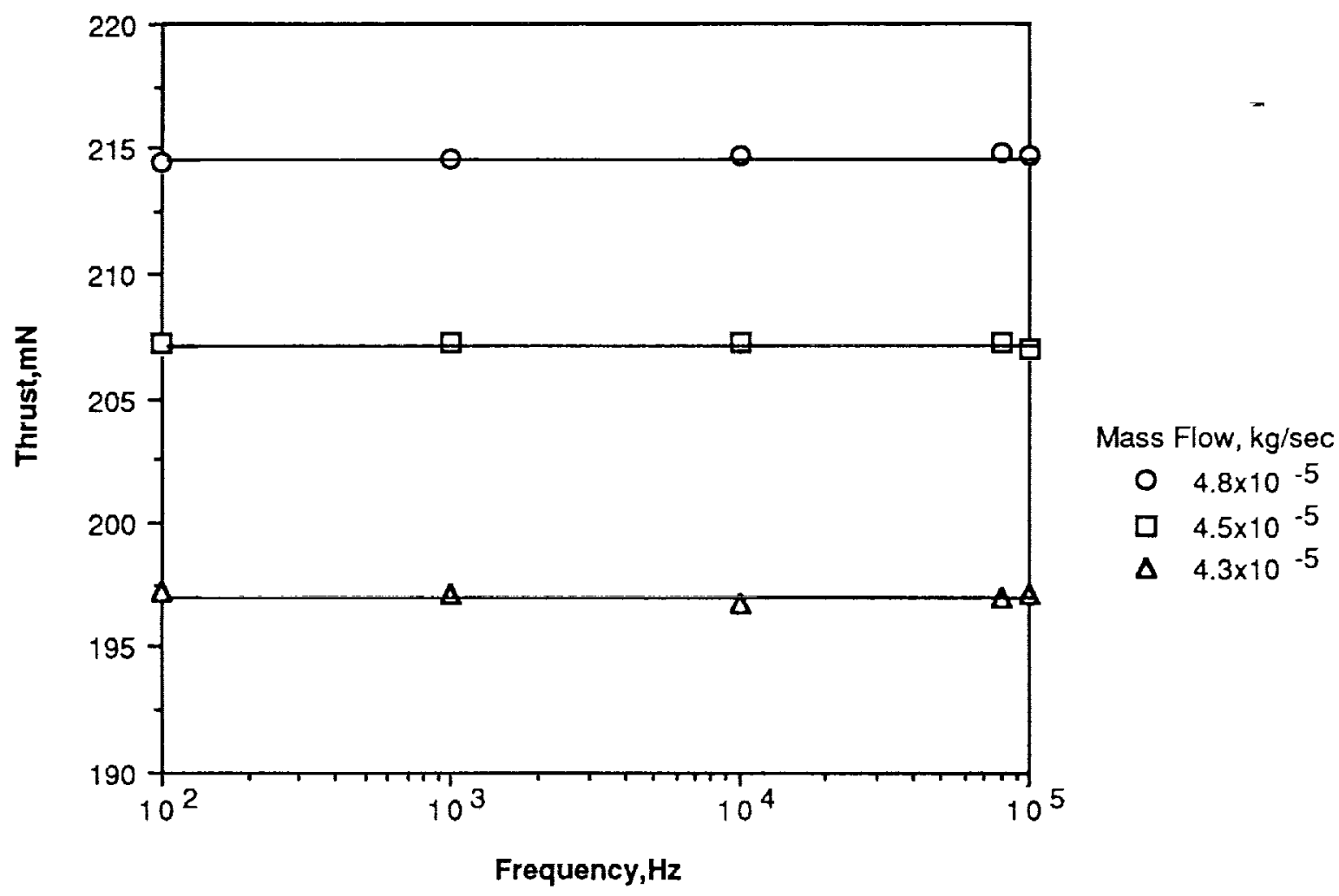

Figure 9. - Thrust vs. ripple frequency for $10 \%$ peak-to-peak ripple amplitude. Horizontal lines denote DC performance levels.

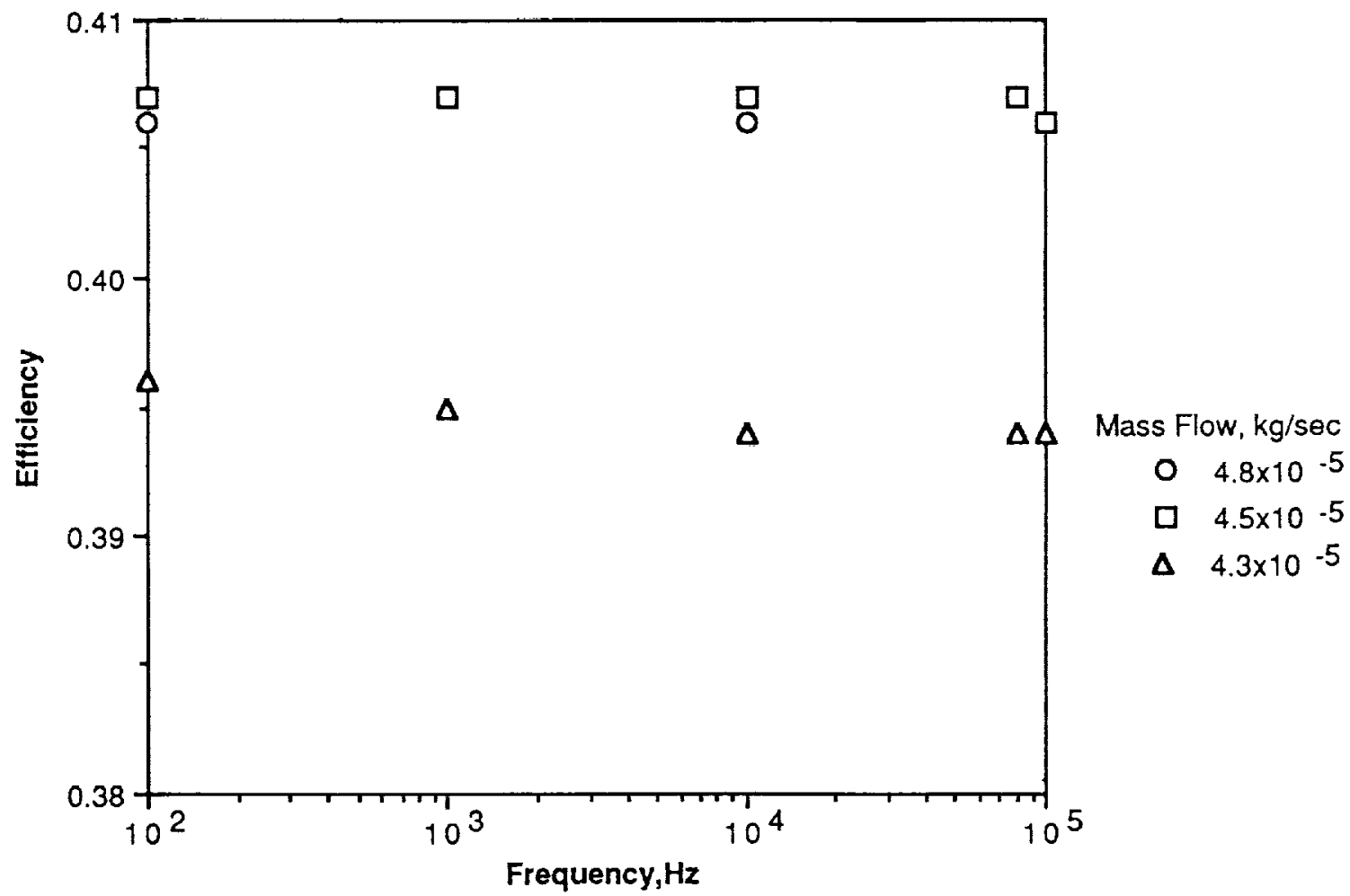

Figure 10. - Efficiency vs. ripple frequency for 10\% peak-to-peak ripple amplitude, thruster 1. 


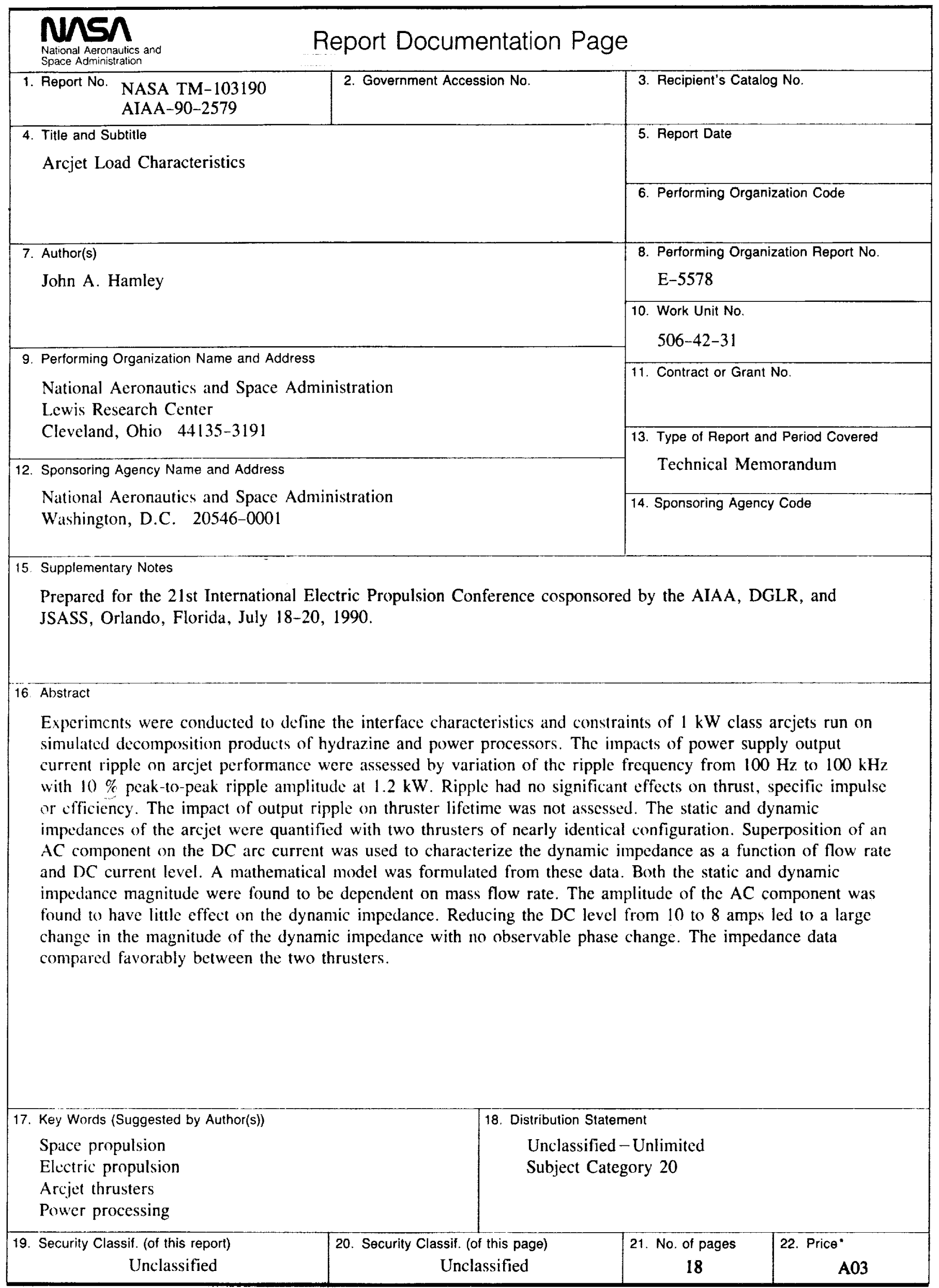


